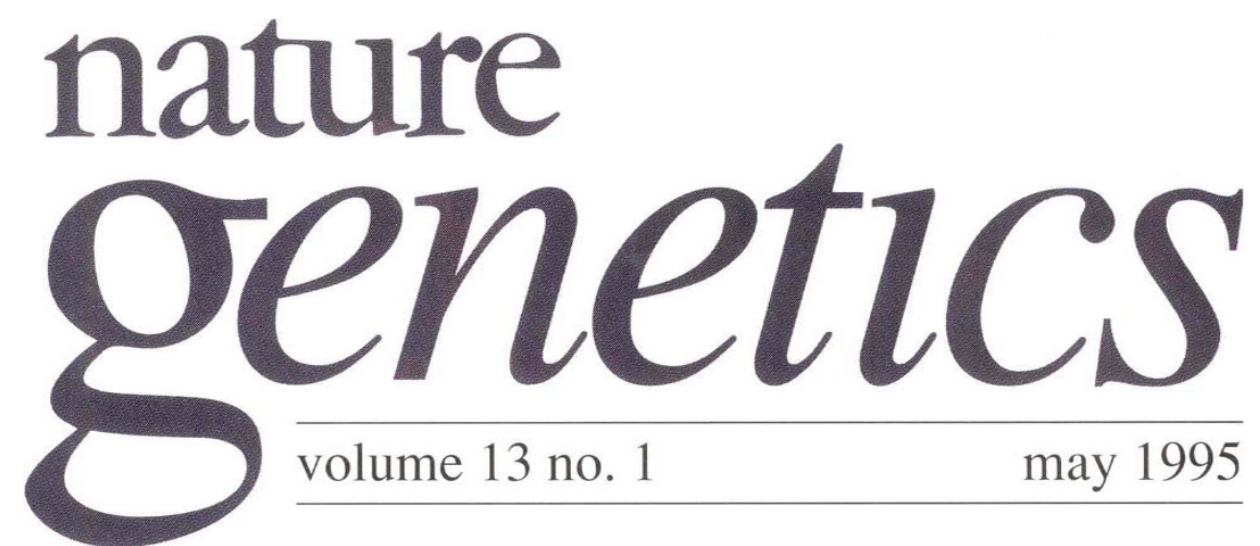

\title{
Capitalizing on the genome
}

Any day now, Millennium Pharmaceuticals, Inc., will become the latest company devoted to the isolation and analysis of human genes involved in disease to go public. The company, based in Cambridge, Massachusetts, hopes to raise $\$ 46$ million by selling 4.6 million shares of Common Stock, and will no doubt be hoping to match the recent highly successful public offerings of five predecessors in the genomics industry, beginning with Incyte Pharmaceuticals in November 1993. Share prices in these companies collectively have outperformed the entire biotechnology sector, and even outstripped the much hyped Internet companies, although prices have declined 10-20\% over the past few months. "Genomics is essential to biotechnology," says Union Bank of Switzerland analyst Matthew Murray. "[These companies] are providing information that drug companies will need to design therapeutics."

Hesitant at first, the pharmaceutical industry is now fully aware of the potential of genome research, clamouring to strike deals, often worth many millions of dollars, with a number of the young genomics companies. 'Big pharma' has come to the realization that the route to the drugs of tomorrow increasingly begins with the gene discoveries of today. This is illustrated nicely by the remarkable $\$ 20$ million deal Amgen struck with the Rockefeller University last year for the rights to the obese gene. Or take SmithKline Beecham (SB), which signed a $\$ 125$ million contract in 1993 with Human Genome Sciences (HGS), based in Rockville, Maryland, for commercial rights to products from newly characterized genes and a $7 \%$ equity stake in the company. SB currently bases $25 \%$ of its drug discovery programmes on genomics, even though the technology has yet to deliver a successful drug. Moreover, research director George Poste predicts that all of SB's research will stem from genomics by the year 2000 . Consistent with this agenda, Peter Goodfellow has been lured away from the Chair of Genetics at Cambridge University to become Senior Vice President of Research at SB later this year.

Performance of stocks in public genome companies
Company

Genome Therapeutics Human Genome Sciences Incyte Pharmaceuticals Myriad Genetics Sequana Therapeutics

$$
\begin{gathered}
\text { Initial public } \\
\text { offering }
\end{gathered}
$$

$\$ 2$ (Sept '94)

$\$ 12$ (Dec '93)

$\$ 7.5$ (Nov'93)

$\$ 18$ (Oct '95)

$\$ 9$ (June '95)

\section{Price}

(4/12/96)

$\$ 95 / 8$

$\$ 37$

$\$ 241 / 2$

$\$ 243 / 8$

$\$ 205 / 8$
Performance

$381 \%$

$208 \%$

$227 \%$

$35 \%$

$129 \%$
So far, the fledgling genomics companies have struck deals with the pharmaceutical industry worth more than $\$ 800$ million (almost as high as the current NIH funding for the genome project). But there is still a long way to go to translate genetic discoveries into successful - in both the medical and commercial sense - therapies. The most profitable drug based on recombinant DNA technology at present is ery- 
thropoietin, sales of which earn almost $\$ 2$ billion annually for Amgen. But it costs a pharmaceutical company $\$ 300$ million on average to develop a drug, and only about one in ten is successfully brought to market. These staggering costs have led to a sharp divide in the long-term strategies of the genomics companies. Most seem content to leave such exorbitant research enterprises to the drug companies. But HGS, among others, believes that it can compete successfully in the world of drug development, and views its current corporate partnerships as more of a short-term relationship to acquire capital than a permanent strategic goal.

Gene kings: There are nine companies that focus on identifying medically relevant human genes, although in some cases other organisms such as mice or bacterial pathogens feature prominently. They fall loosely into two groups: Darwin Molecular Corporation, Mercator Genetics, Millennium Pharmaceuticals, Myriad Genetics and Sequana Therapeutics rely to a large extent on positional cloning to discover genes of interest, although more traditional functional approaches have also paid off. By contrast, Genome Therapeutics, Genset, HGS and Incyte are concentrating on sequencing technologies, using both cDNAs and genomic DNA. (There is, however, considerable overlap in the interests and technologies applied by these companies, and similar programmes underway at the other established companies, such as Merck, SB and Glaxo.) Several of the genomics companies have already reported success using positional cloning: Myriad Genetics discovered the hereditary breast and ovarian cancer gene, $B R C A 1$, and has applied for a patent for $B R C A 2$. After losing out in the bidding for the rights to the obese gene product (leptin), Millennium has scored big by cloning two obesity genes - the leptin receptor and tubby (or "circumferentially challenged," as The Times put it). Screening cDNA databases at HGS has led to the rapid identification of human mismatch repair genes involved in hereditary non-polyposis colon cancer, and other disease genes.

With state-of-the-art resources in areas such as high-throughput sequencing and automated genotyping, strategic agreements with academic collaborators around the world with access to priceless family samples, and a steady stream of researchers eager to leave academia for the business world, many important genetic discoveries are poised to emerge from this new sector. However, to describe these companies as purely interested in gene cloning would be far too simplistic. Some are in the business of selling information, whether it be to other pharmaceutical companies (such as Incyte), or to specific groups of patients such as women at risk of breast cancer, in the case of Myriad Genetics. Others see themselves as pioneering new technologies for drug development.

One of the chief assets of Sequana Therapeutics is access to almost 30,000 DNA samples from patients, families and specific populations in its search for genes for several diseases including osteoporosis, type II diabetes and schizophrenia. The company says it is close to finding a gene for asthma (based on studies of families from the island of Tristan da Cunha). Sequana has applied for a patent on $p 16$ in connection with melanoma (together with the National Cancer Institute). The com-

IMAGE UNAVAILABLE FOR COPYRIGHT REASONS

\footnotetext{
"This is the most sophisticated sequencing equipment on the market. Now just pull the string and we'll start her up."
} pany is putting money gathered from a recent secondary share offering to collecting additional patient material, as well as pursuing functional genomics - the pressing problem of how to translate genetic discoveries into potential therapeutic products.

Other genome companies are also grappling with the need to develop internal expertise in examining the functional properties of potentially important gene products. Official regulations of the Securities and Exchanges Commission bar Millennium Pharmaceuticals staff from discussing their strategies immediately prior to their public stock offering. A recent advertisement, however, notes that Millennium "is clearly poised to become the world's leader in gene-based drug discovery .... We're developing a new generation of diagnostic and therapeutic 
products capable of addressing major diseases at their root cause, rather than merely identifying and treating symptoms." Hyperbole aside, the company has signed corporate partnerships worth $\$ 145$ million over the next five years, mostly in the areas of type II diabetes and obesity, atherosclerosis and asthma, and is broadening its base to include osteoporosis and neuropsychiatric disorders. But like other companies before it, Millennium is facing a potentially protracted patent dispute. A company called Progenitor, Inc., has laid claim to the leptin receptor, which it had cloned two years ago in a quite different context as a 'novel human hematopoietin receptor.'

Mercator Genetics has yet to receive the level of support from the pharmaceutical industry as its rivals, and its prospects were not helped when, last month, Darwin Molecular Corporation narrowly won the race to clone the gene for Werner's syndrome, a fascinating disorder of premature ageing (see page 11). A major hunt for the haemochromatosis gene may prove more successful. Darwin, which received initial funding from Microsoft founders Bill Gates and Paul Allen, is employing large-scale DNA sequencing, informatics, and a directed molecular evolution strategy to develop novel drugs using combinatorial chemistry for major diseases. Rhône-Poulenc Rorer has a four-year agreement with Darwin for therapeutic rights, with particular interest in gene therapy for cancer.

Myriad Genetics was co-founded by Mark Skolnick and Walter Gilbert to search for genes for cancers, heart disease and other complex disorders. The Salt Lake City company leaped into the limelight in 1994 with the study of $p 16$, an important tumour suppressor gene, and then the discovery of BRCA1 (at an estimated cost of $\$ 7$ million), and last December staked a claim for the rights to $B R C A 2$. A complete test for $B R C A 1$ (in contrast to a test for the specific 185delAG mutation, frequent in Ashkenazi Jews, being offered by the Genetics and IVF Institute in Fairfax, Virginia) is expected to be offered this year, and a combined test for both genes is planned for 1997.

Genset, based in Paris but with satellite offices in San Diego and Tokyo, is unique among the genomics companies in that it is concentrating on sequencing the regulatory regions of genes, rather than adopting a more disease-oriented approach. The company has isolated thousands of promoters corresponding to the $5^{\prime}$ regions of various genes by selecting capped RNA transcripts and then screening genomic libraries with the corresponding cDNAs. Aside from compiling a gene inventory, Genset is seeking to apply information it gathers about promoter properties for gene therapy, with special emphasis on nuclear receptor pharmacology and gene isolation. Last year, Genset fended off approaches from at least one other genomics company in recruiting Daniel Cohen, from the Centre d'Etudes Polymorphisme Humain in Paris, to become its research director.

Biology in silico: Two companies have concentrated on widescale cDNA sequencing and analysis. Incyte Pharmaceuticals routinely processes 30,000 cDNA clones per week. The sequence and expression data are deposited in the LIFESEQ $^{\mathrm{TM}}$ (Library of Information For Expressed Sequences) relational database, which so far Incyte has leased to six companies for over $\$ 100$ million. Incyte has deliberately focused on selling information to its clients, and seeks no part in drug discovery itself. "Patents last for 20 years - information lasts forever," proclaims research director Randal Scott. The hard work comes not in generating the raw data, but in analysing it - what Scott likes to call "point-and-click biology." Nevertheless, Incyte recently took a stake in GeneTrace Systems, Inc., to apply mass spectrometry techniques for rapid DNA sequencing.

On the surface, there are several similarities between Incyte and Human Genome Sciences, but lest anyone should be confused, chairman William Haseltine says "Genetics is only part of our thinking. We're not a database company - 


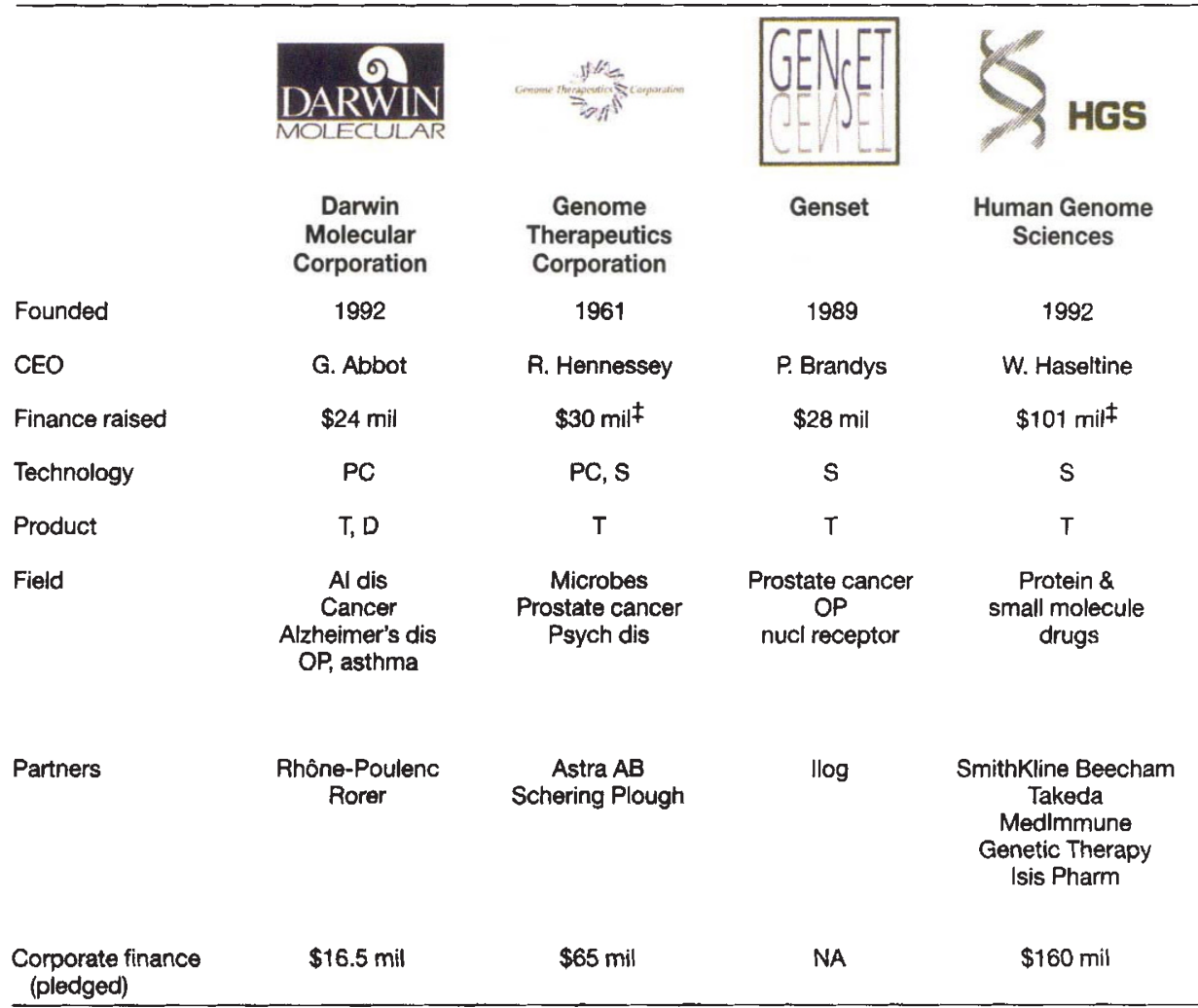

PC, positional cloning; S, sequencing; T, therapeutics; D, diagnostics; I, information; Al, autoimmune; OP, osteoporosis. $\ddagger$, not including value of outstanding shares. *, Glaxo investment undisclosed. Source: Silverman, E. Genomics: An Investor's Guide (Punk, Ziegel \& Knoell, New York, 1996).

we're not an 'Incyte." Then again, HGS is not into presymptomatic genetic testing either. "There's no demonstrated market for predictive genetic tests," Haseltine argues. Hasetine says that HGS "has isolated and characterized a virtually complete set of human genes," having built a catalogue of 850,000 cDNA sequences from nearly 600 different human cDNA libraries over the past few years. Working from non-normalized libraries, the HGS database reveals information on the relative abundance of each transcript in an array of different cell and tissue types. This, says Haseltine, is leading to "more good opportunities than we know what to do with." For example:

- Osteoporosis: $4 \%$ of the transcripts from an active osteoclast cDNA library (provided by SB) encode a novel cathepsin protease. SB has since generated specific inhibitors of the enzyme that are said to inhibit bone degradation in a model system.

- An abundant transcript from pineal gland (previously cloned but not considered particularly interesting) encodes a secreted, highly hydrophilic protein that has all the hallmarks of an important hormone.

- Prostate cancer: several genes that are specifically switched on during prostate carcinogenesis have been isolated, including markers such as PSA.

HGS says it intends to discover medically useful genes in areas such as infectious, inflammatory and autoimmune diseases, in order to convert that knowledge into "proprietary product opportunities". More than 100 patent applications have been filed, as the company has characterized more than 50 novel G-proteincoupled receptors and at least a dozen new chemokine molecules. But in the long term, HGS wants to develop products itself, and believes it has the resources and expertise to succeed. In January, HGS teamed up with the agricultural biotechnology company Pioneer Hi-bred to study the maize genome. It has also announced that it has sequenced the genome of Staphylococcus aureus, which, in 


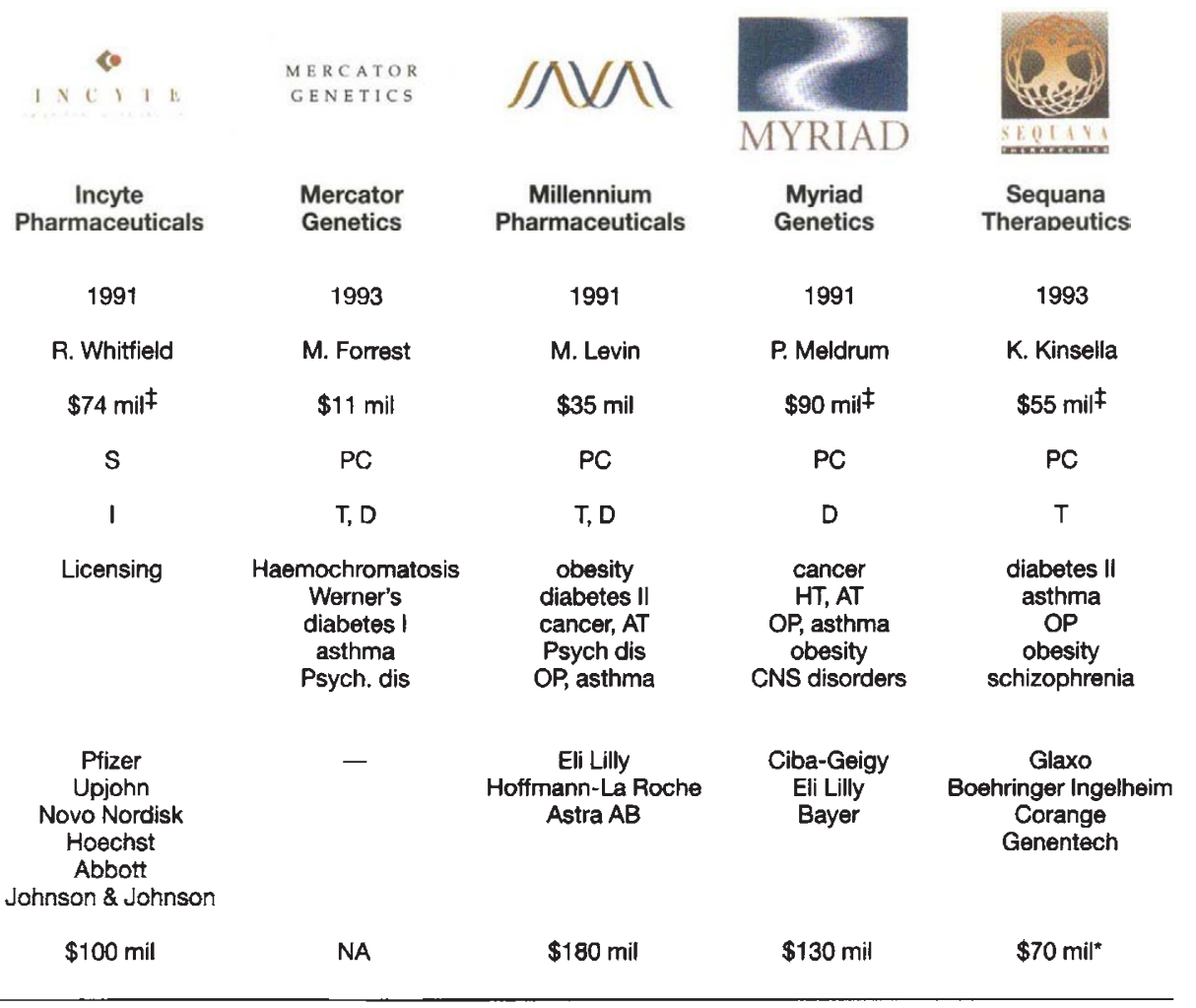

conjunction with MedImmune, it hopes to translate into antibiotics and vaccines. HGS is also collaborating with Hoffman-La Roche to sequence the genome of Streptococcus pneumoniae.

The value of microorganisms seen by HGS is shared by the oldest of the genomics companies, Genome Therapeutics, which was founded in 1961 under the name Collaborative Research. The company achieved a certain notoriety during the race for the cystic fibrosis gene in the mid 1980s, during which one executive claimed "We own chromosome 7!" In 1994, Genome Therapeutics announced the sequencing of the genome for Helicobacter pylori, the pathogen responsible for peptic ulcers. The rights to the genome were sold to the Swedish company Astra $\mathrm{AB}$ for $\$ 22$ million last year, and the sequences of $S$. aureus and Mycobacterium tuberculosis are almost finished. (Britain's Wellcome Trust recently announced that it is supporting another effort to sequence the tuberculosis bacterium.) A deal with Schering-Plough could be worth over $\$ 40$ million over the next four years. But while best known for its bacterial genomics work, Genome Therapeutics is once again turning to human genomics as a second "commercialization platform", as Chairman Robert J. Hennessey puts it.

The new genomics companies have a long way to go to match their more established rivals. Amgen, for example, has a market capitalization value of more than $\$ 16$ billion, whereas most of the genomics companies are about \$100-200 million. The next few years will tell whether the excitement and high expectations on Wall Street will be fulfilled. Many projects will doubtless fail or be snatched away by other groups, and commercial success may depend $r$ on the whim of the patent office as much as anything. There is little doubt, however, that the face of biomedical research will be transformed irrevocably by the new genomics powers. 